\title{
Controlled Re-Injury of a Thigh Muscle Tear in a Soccer Player: a Case Study
}

\author{
Alvaro N Gurovich, PT, PhD, FACSM ${ }^{1)}$ \\ 1) School of Kinesiology and Physical Therapy, Pontificia Universiadad Católica de Valparasío: \\ Av. Brasil 2950 Valparasio, Chile. \\ Current affiliation: Department of Applied Medicine and Rehabilitation, Indiana State University \\ Sycamore Center for Wellness \& Applied Medicine: 567 North 5th Street, Terre Haute, IN 47809, \\ USA. TEL: +1 812-237-8232,FAX:+1812-237-3615,E-mail: Alvaro.Gurovich@indstate.edu
}

\begin{abstract}
Purpose] This case study describes an interesting therapeutic approach to an athlete's muscle injury, which was erroneously diagnosed and treated for the first 48 hours. [Case] During a regular season match, a 17 yearold male, soccer player was hit on his front thigh while he was kicking the ball. The first diagnosis was a contusion, and the player was treated with warm-packs for 48 hours. Ultrasound images revealed a massive muscle tear on the left vastus intermedius of the quadriceps muscle 60 hours after injury. The rehabilitation approach was based on three therapeutic principles: 1) to prevent inflammatory secondary damage, we performed a controlled re-injury to start with a new acute injury; 2) use of physical agents as acute control of the inflammation process; and 3) overlapping rehabilitation phases, such as rest, pain control, healing process, muscle strengthening and aerobic training, to reduce total rehabilitation time. [Results] Weekly ultrasound images showed a total repair after 4 weeks of treatment. Due to the effectiveness of the rehabilitation program the athlete was able to play competitively 35 days after the injury and no re-injury was observed over a 1 year follow-up. [Conclusion] The therapeutic approach used in this case study, which involved the prevention of secondary damage and the overlap of rehabilitation phases, was effective and time efficient.

Key words: Muscle injury, Rehabilitation, Ultrasound
\end{abstract}

(This article was submitted Sep. 7, 2011, and was accepted Oct. 24, 2011)

\section{INTRODUCTION}

Muscle injuries are considered the most common athletic injury reaching up to $67 \%$ of injuries, depending on the sport 1,2 , and quadriceps strain accounts for one third of all injuries suffered by professional soccer players $\$$. This kind of injury can be considered the most severe soft tissue injury, because it affects not just a component of the locomotor system, but the one that is the engine of movementst, 5 . Current research has shown that the muscle is much more than a contractile/elastic combined system 4 . 6 . In fact, muscle is a complex mechanical system that has other functions in addition to the action of contraction. For instance, muscle is related to myofascial force transmission 6,7 , through the extracellular collagen matrix 9 , which guarantees optimal biomechanical performance 7 . For this reason, when there is a muscle injury, there are three pathophysiologic events to be concerned about: the inflammatory process 8 , the repair of the contractile system ${ }^{10,11}$, and the repair of the collagen system 12,13.

Depending on the extent of the muscle tear, the time to a complete healing of the injury is about 14 to 45 days 14 . Secondary damage, repair, and remodelling phases are combined with an active inflammatory process that elicits cellular and proliferative reactions $9,13,15-17$. However, the com- plete healing of the injury does not guarantee a functional muscle. Decreased muscle strength and cardiovascular and muscle de-training prevail over physiological performance within 1 to 3 weeks rest from regular training activities ${ }^{14}$. Therefore, participation in full sport activity may be delayed 7 to 9 weeks from the original injury.

After an accurate diagnosis has been established, the usual rehabilitation process is divided into 4 treatment phases: 1) minimization of deleterious local effects of the acute injury, 2) period for proper healing, 3) maintenance of other components of athletic fitness, and 4) return to normal athletic function ${ }^{14}$. Traditionally, each of these phases has an individual approach, waiting for the end of each phase to start the next one. Moreover, the proper healing phase is normally treated with rest and drugs 18,19 .

Although therapeutic ultrasound (US) is normally recommended for muscle skeletal rehabilitation 20,21 , the scientific evidence from animal studies is not promising $20,22,23$. However, these previous studies focused on myofibrillar changes rather than fibroelastic components such as the muscle extracellular collagen matrix, which has an important role in muscle force production 5 . From this viewpoint, there is evidence that mechanical stimuli like therapeutic ultrasound 22, 24, 25 and early mobilization 13,16 may enhance the muscle injury recovery, stimulating fibroblast metabolism. 
Finally, to the best of our knowledge, there are no reports of endurance training during the healing phase to prevent a decrease in the overall aerobic capacity of patients. Moreover, there is no evidence that an endurance training protocol is deleterious to muscle healing. Therefore, muscle injury recovery and cardiovascular performance could be integrated to shorten the time to retrun to regular athletic function.

The purpose of this case report is to present a different approach to muscle injury rehabilitation. The use of US, combined with stretching and strengthening exercises, and early aerobic conditioning allowed the full recovery of a soccer player within 5 weeks from the original injury, which was a $9 \times 3 \times 3 \mathrm{~cm}$ muscle tear on the left vastus intermedius of the quadriceps muscle.

\section{CASE}

\section{History}

A 17 year-old male professional soccer player received a high impact hit on his left thigh. Approximately half way through the second half of a midseason game, he received a kick on his front left thigh while he was kicking at the goal. The player retired from the game for three minutes for examination, then he continued to play, scoring two more times. He finished the game walking with difficulty and pain. He went to a hospital emergency room where the diagnosis was a thigh contusion. He was asked to place heat packs on his thigh and rest for one week. Forty-eight hours after the injury, he was examined by a sport specialist physical therapist.

\section{Physical Therapy Evaluation}

Inspection: the patient showed a haematoma about the size of the middle third of his front left thigh.

Palpation: a painful (visual analogue scale $(\mathrm{VAS})=7$ ), organized and solid edema was evidenced.

Functional Survey: painful passive mobilization (VAS = 8) with $90^{\circ}$ maximal knee flexion end, and painful active knee extension $(\mathrm{VAS}=9)$.

The neurological survey was negative for paresthesias and large nerve compromise.

\section{Tests and Results}

After clinical evaluation, ultrasound imaging was performed. The left front thigh longitudinal and cross-sectional views (Fig. 1 and Fig. 2, respectively) show a $9 \times 3 \times 3 \mathrm{~cm}$ transverse tear of the middle third of the vastus intermedius of the quadriceps muscle, an encapsulated haematoma, and liquid collection, likely indicating an active inflammatory process. No fracture or bony abnormalities were seen on the left thigh anterior-posterior and lateral X-rays. The first ultrasound imaging tests were performed 60 hours after the trauma, and they were performed every two weeks to observe the healing evolution.

After the physical exam and the image tests, the working diagnosis was a massive vastus intermedius transverse tear, with concomitant active inflammatory process and quadriceps muscle contracture.

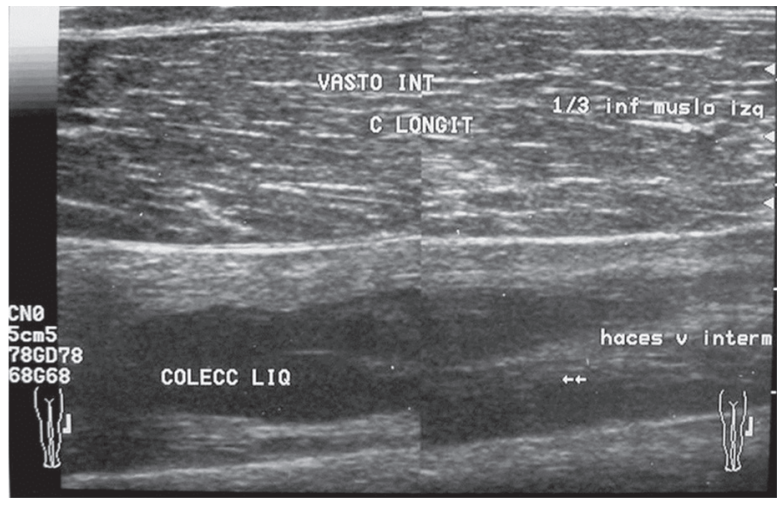

Fig. 1. Ultrasound image of the left front thigh (longitudinal view) 60 hours after injury. Bottom of the figure, massive vastus intermedius muscle tear with liquid collection and encapsulated haematoma. VASTO INT = vastus medialis; C LONGIT $=$ longitudinal view; $1 / 3 \mathrm{inf}$ muslo izq $=$ left thigh distal third; COLLECC LIQ = liquid collection; haces $\mathrm{v}$ interm $=$ vastus intermedius muscle fibers.

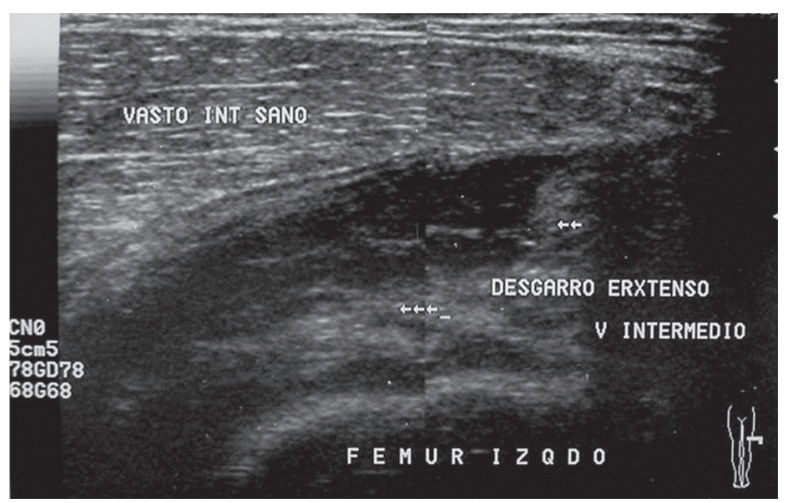

Fig. 2. Ultrasound image of the left front thigh (cross-sectional view) 60 hours after injury. Middle part of the figure, massive vastus intermedius muscle tear. VASTO INT SANO = healthy vastus medialis; DESGARRO ERXTENSO V INTERMEDIO = massive vastus intermedius muscle tear; FEMUR IZQDO = Left femur.

\section{Physical Therapy Rehabilitation}

The intervention was designed on a weekly improvement base. The clinical evolution of the patient was tested every Monday, when management of session time and exercise intensity were performed. After 11 daily sessions, Tuesday of the first week through Friday of the second week, the session frequency was reduced to 5 days per week. Each treatment session lasted for 30 minutes during the first week, to 120 minutes during the last week. Figure 3 shows the time/phase interaction of the overall treatment. Verbal informed consent to the intervention procedures and acknowledgement of the risks was given by the patient and his legal guardian.

First Week: Due to the poor acute clinical management of the patient, it is likely that the active inflammatory process was in the proliferative phase, in which muscle fibro- 


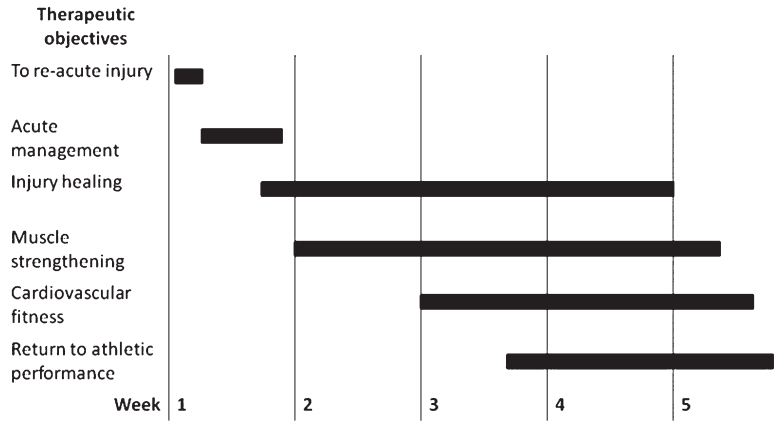

Fig. 3. Summary of the treatment approach, showing time/ phase interaction. Rehabilitation phases were overlapped according to the patient's progress.

sis would have begun. Therefore, it was decided to perform a controlled re-injury of the muscle using diathermy and stretching for two days. Immediately after the second session, compressive cryotherapy for 15 minutes was used to minimize the deleterious local effects of the acute injury ${ }^{17}$ 26, and the patient was asked to repeat it each hour, during daylight, until the next session. From the third to the 6 th day, the injury was treated as an acute muscle tear, using compressive cryotherapy and transcutaneous electric neurostimulation (TENS) for 15 minutes, and US with a very low spatial average temporal average $\left(\mathrm{SATA}=0.05 \mathrm{~W} / \mathrm{cm}^{2}, 10\right.$ $\mathrm{min})$, at the start of the proper healing phase.

Second Week: Pain and range of motion (ROM) were assessed at the beginning of each week. Pain during passive mobilization decreased (VAS $=6$ ) with no change in passive ROM ( $90^{\circ}$ maximal knee flexion). Sessions began with compressive cryotherapy and TENS for 15 minutes, then US (SATA $=0.10 \mathrm{~W} / \mathrm{cm}^{2}, 10$-min). During this week therapeutic exercises were started, including stretching and quadriceps muscular strengthening at 50\% maximal isometric voluntary contraction (MIVC) on an open kinetic chain exercise machine (isotonic unilateral leg extension). US and stretching were oriented to improve healing. Muscular strengthening of the involved limb was performed to prevent significant injury-related strength loss. Muscular strengthening of the non-involved limb was performed to maintain athletic performance.

Third Week: Pain during passive mobilization decreased $(\mathrm{VAS}=4)$ with an increase in passive ROM $\left(110^{\circ}\right.$ maximal knee flexion). Sessions began with 30 minutes of aerobic exercise on a static bicycle at 50 to $70 \% \mathrm{VO}_{2} \mathrm{max}$, estimated from the theoretical maximal heart rate7, muscular strengthening at $75 \%$ MIVC using unilateral closed kinetic chain exercises, and stretching. US (SATA $=0.20 \mathrm{~W} / \mathrm{cm}^{2}$, 10-min), compressive cryotherapy, and TENS for $15 \mathrm{~min}$ utes were switched to the end of the session. Therapeutic exercise, aerobic and strengthening exercises, were oriented to the cardiovascular fitness maintenance phase and the beginning of the return to normal athletic function phase, while US and stretching were still oriented to the injury healing phase.

Fourth Week: Pain during passive mobilization decreased
$(\mathrm{VAS}=1)$ with an increase in passive $\mathrm{ROM}\left(135^{\circ}\right.$ maximal knee flexion). Sessions began with 60 minutes of aerobic exercise on a static bicycle, and intensities alternated between $50-70 \% \mathrm{VO}_{2} \max$ and $85-95 \% \mathrm{VO}_{2} \max$ sessions. TENS was applied during muscular strengthening exercises $(85 \%$ MIVC) combining unilateral open and closed kinetic chain exercises. In addition, assisted stretching and mobility and agility drills, with and without a soccer ball, were included in the protocol. US (SATA $=0.20 \mathrm{~W} / \mathrm{cm}^{2}, 10$-min) was performed at the end of the session. Injury healing, cardiovascular fitness maintenance, and return to normal athletic function phases were present in this week. No pain and full ROM were observed at the end of the fourth week.

Fifth Week: After a control ultrasound imaging, the patient was allowed to train with his team, using ice and stretching after each training session. At the end of the week he played in a regular season match, without pain or any impairment.

\section{RESULTS}

After the fourth week of treatment, a control ultrasonography was performed. The longitudinal view (Fig. 4) showed an almost completely healed quadriceps vastus intermedius, without any liquid collection or calcification traces. The cross-sectional view (Fig. 5) showed the same longitudinal healing status, but some fibrotic or calcified fibres were present. As the left knee extension force was $95 \%$ of the right one at this time, the patient was allowed to train with his team, under observation for complications during the first week of soccer practice. As no difficulties were observed, the patient was authorized to play half time in a regular season match. No pain or contracture followed the match, and the patient was stronger and fitter than many of his team-mates. He finished the season as the championship's highest scorer.

At one-year follow-up, the patient did not show any significant physical problem, no calcification or fibrosis were seen on ultrasound images (Fig. 6), and the injury was fully recovered.

\section{DISCUSSION}

Although muscle injuries are the most common athletic injury 1,2 , little information is available to determine the best clinical approach for treating these injuries $10,11,13,14,16,24$. Controversial results in animal models may not give useful information 3,24 , neither on treatment protocols nor chance of re-injury ${ }^{28}$.

Using RICE (Rest, Ice, Compress and Elevation) after any acute muscle skeletal injury is a universal consensus 13 . $14,16,17,26$. Unfortunately, this was not the first aid treatment received by the patient presented in this case, who was asked to apply heat during the first 48 hours after the trauma. This erroneous intervention placed the sport specialist physical therapist in a tough situation: 1) to begin a traditional subacute treatment during the early inflammatory proliferative phase 9,15 , or 2) to carefully perform a controlled de novo injury and start all over with the RICE concept. In this case, the physical therapist did not choose the traditional therapeutic pathway, which probably would have taken longer for 
full recovery. In contrast, using a less traditional approach the athlete was able to maximally perform within 5 weeks.

Another important decision taken was to start the exercise phase, only 10 days after injury, even though the patient was still in pain (VAS $=5$ ) taking advantage of his athletic history. This decision helped to accelerate the healing phase ${ }^{13}$ 117 and shorten the "sedentary" status of the athlete" preventing detraining and allowing a faster returning to a competitive state.

Improvements in muscle force and viscoelastic properties have been shown to be beneficial for prevention of and recovery from muscle injuries $19,28,30$. In the present clinical case, early muscle strengthening and stretching were performed early during the second treatment week. This decision, along with interaction of the therapeutic phases (Fig. 3), was taken not only in consideration of the muscle healing and early return to normal athletic state, but also as a secondary prevention strategy. The final outcome with no re-injury a year after the original injury demonstrated that the overall strategy was successful.

One common sequel of massive muscle injury is the production of myositis ossificans, which are calcifications of fibrous tissue after the inflammatory proliferative phase ends ${ }^{13,16,31}$. In the present case, myositis ossificans was expected in response to the massive muscle injury. Moreover, some fibrotic/calcified images were seen in the ultrasonography at the end of the fourth week of treatment (Fig. 5); however, after one year of follow-up no calcified scar tissue was detected on the ultrasound images (Fig. 6) and no re-injury was reported. Myositis ossificans prevention in this case can be explained by the overlap of the treatment phases, including early stretching and strengthening ${ }^{13,10}$, active cycling, and use of therapeutic ultrasound (US) ${ }^{32,33}$.

Although there is no promising animal or clinical evidence that US can help repair muscle injuries $0-23$, there is plenty of evidence showing the effects of US in collagen repair and re-synthesis $25,33-41$. The use of US in the present clinical case was oriented at improving muscle collagen extracellular matrix (CEM) repair, based upon US effects on fibroblast proliferation and collagen synthesis 25,39 . In fact, muscle CEM has an important role in muscle function, accounting for up to $35 \%$ of the overall muscle force production 6.7 . It is hard to say that US was the only factor which improved the patient's injury because of the multifactor therapeutic approach; however, it may have played an important role in preventing myositis ossificans and re-injury.

Considering that the time for a safe return to full athletic activity after a muscle injury is 9 to 14 weeks $\$$ from the original trauma, the rehabilitation protocol presented in this clinical case may be considered successful. Furthermore, the controlled re-injury could be considered 'therapeutic'. Only 5 weeks after a massive muscle tear, the athlete was training with his team and playing in a regular season game. Moreover, one year after finishing the treatment, no re-injury was observed and the athlete continued to perform at his best physical strength.

Not all muscle injuries have the same evolution as the one presented in this study. One key factor for a controlled injury evolution is to tackle the inflammatory process when

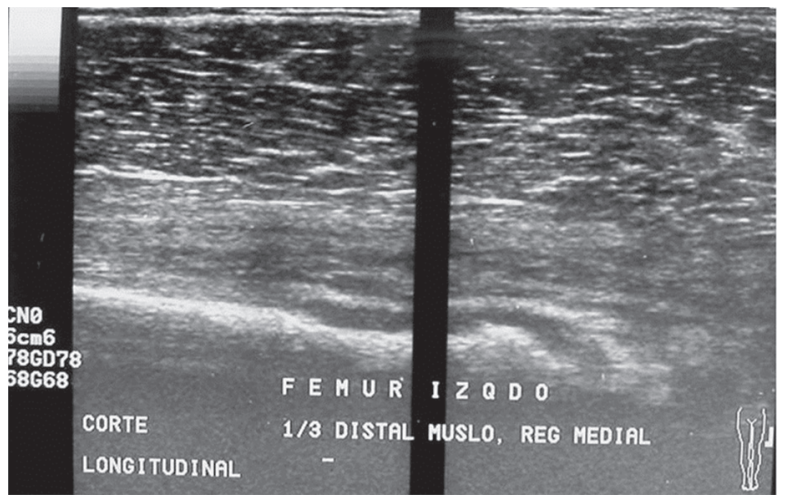

Fig. 4. Ultrasound image of the left front thigh (longitudinal view) 4.5 weeks after injury. There is no liquid collection or calcification trace. FEMUR IZQDO $=$ Left femur; $1 / 3$ DISTAL MUSLO = thigh distal third; REG MEDIAL = medial zone; CORTE LONGITUDINAL $=$ longitudinal view

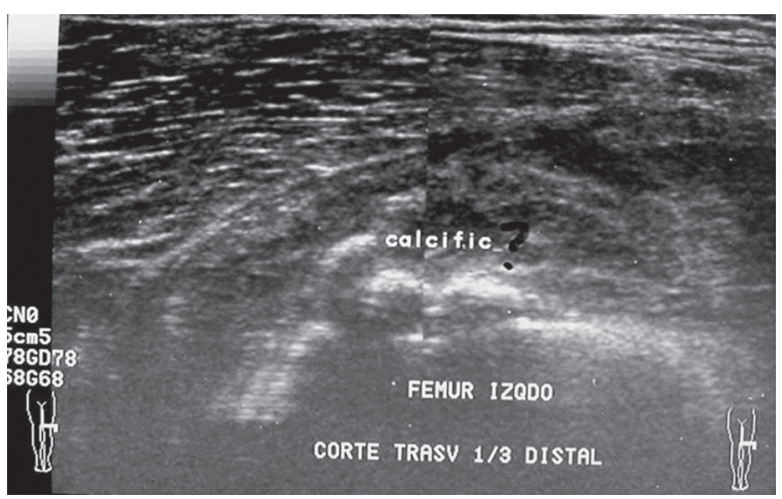

Fig. 5. Ultrasound image of the left front thigh (cross-sectional view) 4.5 weeks after injury. Middle part of the figure suggests fibrosis/calcification of muscle scar. calcific? = probable calcifications; FEMUR IZQDO $=$ left femur; CORTE TRANSV 1/3 DISTAL $=$ crosssectional view of the distal third.

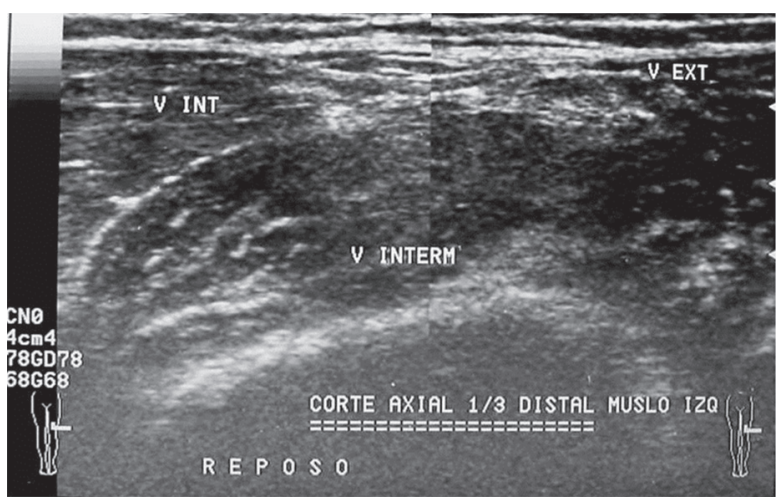

Fig. 6. Ultrasound image of the left front thigh (cross-sectional view) one year after injury. Middle part of the figure suggests full recovery. V INT = vastus medialis; V $\mathrm{EXT}=$ vastus lateralis; $\mathrm{V}$ INTERM $=$ vastus intermedius; CORTE AXIAL = cross-sectional view; $1 / 3$ DISTAL MUSLO IZQ = left thigh, distal third; REPOSO $=$ rest 
it starts $17,23,26$. Once inflammatory secondary injury is prevented, the therapeutic aim should be to improve tissue healing and the patient's function. In the present case, the therapeutic phases were overlapped to optimize recovery time. Furthermore, new knowledge integrating US's collagen synthesis effects, early resistance exercise, and early aerobic exercise were used to improve the patient's outcomes. This new integrated approach could be considered a first step in the design of muscle injury rehabilitation protocols. Thus, this new protocol can provide a new window of opportunity for further research and treatment in the prevention and care of muscle injuries.

\section{ACKNOWLEDGEMENTS}

I would like to thank Dr. Pedro Santander who performed the ultrasound images along with the treatment and taught me how to interpret them.

\section{REFERENCES}

1) Kibler WB: Clinical aspects of muscle injury. Med Sci Sports Exerc, 1990 , 22: 450-452. [Medline]

2) Orchard J: Biomechanics of Muscle Strain Injury. N Z J Sports Med, 2002, 30: 92-98.

3) Volpi P, Melegati G, Tornese D, et al.: Muscle strains in soccer: a five-year survey of an Italian major league team. Knee Surg Sports Traumatol Arthrosc, 2004, 12: 482-485. [Medline] [CrossRef

4) Herzog W: Mechanical Muscle Models and Their Application to Force and Power Production. In: Strength and Power in Sport. Blackwell Scientific Publications, 2003, pp 154-183.

5) Ji LL: Exercise-induced modulation of antioxidant defense. Ann N Y Acad Sci, 2002, 959: 82-92. Medline CrossRef

6) Huijing PA: Muscle as a collagen fiber reinforced composite: a review of force transmission in muscle and whole limb. J Biomech, 1999, 32: 329345. [Medline CrossRef

7) Yucesoy CA, Koopman BH, Huijing PA, et al.: Three-dimensional finite element modeling of skeletal muscle using a two-domain approach: linked fiber-matrix mesh model. J Biomech, 2002, 35: 1253-1262. [Medline [CrossRef]

8) Kovanen V: Intramuscular extracellular matrix: complex environment of muscle cells. Exerc Sport Sci Rev, 2002, 30: 20-25. [Medline] CrossRef

9) Pryde JA: Inflammation and tissue repair. In: Physical Agents in Rehabilitation: from Research to Practice. Philadelphia: W.B. Saunders, 2003, pp 13-38.

10) Proske U, Morgan DL: Muscle damage from eccentric exercise: mechanism, mechanical signs, adaptation and clinical applications. J Physiol, 2001, 537: 333-345. [Medline] CrossRef

11) Proske U, Allen TJ: Damage to skeletal muscle from eccentric exercise Exerc Sport Sci Rev, 2005, 33: 98-104. [Medline] [CrossRef]

12) Clarkson PM, Sayers SP: Etiology of exercise-induced muscle damage. Can J Appl Physiol, 1999, 24: 234-248. IMedline [CrossRef]

13) Järvinen TA, Jarvinen TL, Kaariainen M, et al.: Muscle injuries: biology and treatment. Am J Sports Med, 2005, 33: 745-764. Medline CrossRef

14) Herring SA: Rehabilitation of muscle injuries. Med Sci Sports Exerc, 1990, 22: 453-456. Medline

15) Clarkson PM, Hubal MJ: Exercise-induced muscle damage in humans. Am J Phys Med Rehabil, 2002, 81: S52-S69. Medline [CrossRef

16) Järvinen TA, Kaariainen $M$, Jarvinen $M$, et al.: Muscle strain injuries Curr Opin Rheumatol, 2000, 12: 155-161. Medline CrossRef

17) Merrick MA: Secondary injury after musculoskeletal trauma: a review and update. J Athl Train, 2002, 37: 209-217. [Medline]
18) Garrett WE Jr: Muscle strain injuries: clinical and basic aspects. Med Sci Sports Exerc, 1990, 22: 436-443. [Medline

19) Garrett WE Jr: Muscle strain injuries. Am J Sports Med, 1996, 24: S2-S8. Medline

20) Järvinen TA, Järvinen TL, Kaariainen M, et al.: Muscle injuries: optimising recovery. Best Pract Res Clin Rheumatol, 2007, 21: 317-331. [MedlineCrossRef

21) Beiner JM, Jok1 P: Muscle contusion injuries: current treatment options. J Am Acad Orthop Surg, 2001, 9: 227-237. Medline

22) Rantanen J, Thorsson O, Wollmer P, et al.: Effects of therapeutic ultrasound on the regeneration of skeletal myofibers after experimental muscle injury. Am J Sports Med, 1999, 27: 54-59. [Medline

23) Wilkin LD, Merrick MA, Kirby TE, et al.: Influence of therapeutic ultrasound on skeletal muscle regeneration following blunt contusion. Int $\mathrm{J}$ Sports Med, 2004, 25: 73-77. Medline CrossRef

24) Karnes JL, Burton HW: Continuous therapeutic ultrasound accelerates repair of contraction-induced skeletal muscle damage in rats. Arch Phys Med Rehabil, 2002, 83: 1-4. [Medline [CrossRef

25) Ramirez A, Schwane JA, McFarland C, et al.: The effect of ultrasound on collagen synthesis and fibroblast proliferation in vitro. Med Sci Sports Exerc, 1997, 29: 326-332. [Medline [CrossRef

26) Merrick MA, McBrier NM: Progression of secondary injury after musculoskeletal trauma-a window of opportunity? J Sport Rehabil, 2010, 19: 380-388. Medline

27) American College of Sports Medicine: Guideliunes for Exercise Testing and Prescription. 6th ed. Philadelphia: Lippincott Williams \& Wilkins, 2000.

28) Orchard J, Best TM: The management of muscle strain injuries: an early return versus the risk of recurrence. Clin J Sport Med, 2002, 12: 3-5. Medline [CrossRef

29) Kannus P, Parkkari J, Jarvinen TL, et al.: Basic science and clinical studies coincide: active treatment approach is needed after a sports injury. Scand J Med Sci Sports, 2003, 13: 150-154. [Medline [CrossRef

30) Malliaropoulos N, Papalexandris S, Papalada A, et al.: The role of stretching in rehabilitation of hamstring injuries: 80 athletes follow-up. Med Sci Sports Exerc, 2004, 36: 756-759. [Medline CrossRef

31) Armfield DR, Kim DH, Towers JD, et al.: Sports-related muscle injury in the lower extremity. Clin Sports Med, 2006, 25: 803-842. IMedline CrossRef

32) Wieder DL: Treatment of traumatic myositis ossificans with acetic acid iontophoresis. Phys Ther, 1992, 72: 133-137. [Medline

33) Ebenbichler GR, Erdogmus CB, Resch KL, et al.: Ultrasound therapy for calcific tendinitis of the shoulder. N Engl J Med, 1999, 340: 1533-1538. Medline [CrossRef

34) Tsai WC, Chen JY, Pang JH, et al.: Therapeutic ultrasound stimulation of tendon cell migration. Connect Tissue Res, 2008, 49: 367-373. Medline CrossRef

35) Sparrow KJ, Finucane SD, Owen JR, et al.: The effects of low-intensity ultrasound on medial collateral ligament healing in the rabbit model. Am J Sports Med, 2005, 33: 1048. [Medline] CrossRef

36) Mayer F, Hirschmüller A, Müller S, et al.: Effects of short-term treatment strategies over 4 weeks in Achilles tendinopathy. Br J Sports Med, 2007, 41: e6. Medline [CrossRef

37) Yeung CK, Guo X, Ng YF: Pulsed ultrasound treatment accelerates the repair of Achilles tendon rupture in rats. J Orthop Res, 2006, 24: 193-201. Medline [CrossRef

38) Rompe JD, Furia JP, Maffulli N: Mid-portion Achilles tendinopathy-current options for treatment. Disabil Rehabil, 2008, 30: 1666-1676. [Medine CrossRef

39) Tsai WC, Pang JH, Hsu CC, et al: Ultrasound stimulation of types I and III collagen expression of tendon cell and upregulation of transforming growth factor. J Orthop Res, 2006, 24: 1310-1316. Medline [CrossRef

40) Warden SJ, Brukner P: Patellar tendinopathy. Clin Sports Med, 2003, 22: 743. Medline [CrossRef

41) Kader D, Saxena A, Movin T, et al.: Achilles tendinopathy: some aspects of basic science and clinical management. Br J Sports Med, 2002, 36: 239. [Medline [CrossRef 